\title{
Criação na perspectiva da diferença ${ }^{1}$
}

Paola Zordan ${ }^{2}$

\section{Resumo}

O texto apresenta conceitos de criação em teorias ligadas as artes visuais e pesquisas ligadas à área da educação. A finalidade é mostrar o modo como o criar infinitivo, força inegável de toda aprendizagem, se coloca perante a perspectiva da Filosofia da Diferença, em especial no pensamento de Gilles Deleuze. Num plano geofilosófico é traçada a problematização noológica da criação, visto que o criar, em si, é um problema imanente a todo o pensar. Ao criar se contrapõe o uso estereotipado, clichê, das opiniões do senso comum. A criação exige algo diferente do já sabido, conhecido, pensado, de modo a arrastar o pensamento para zonas indeterminadas de um caos inimaginável que só a arte é capaz de exprimir. Impossível de ser colada à imagens prontas, a noologia da criação só pode ser analisada junto as regularidades e inconstâncias dos fluxos da Terra.

Palavras chave: criar, Deleuze, filosofia da criação, plano de imanência.

\section{Abstract}

It is a discussion about concepts of creation such as they are presented in theories connected both to Visual Arts and to research in Education. Its objective is to situate the act of creation - as it expresses itself in its infinitive mode, to create, undeniably a strong power which is present in every act of learning - in relation to the perspective of the Philosophy of Difference and, more specifically, to the thought of Gilles Deleuze. The text tries to sketch a noological questioning of the act of creation from the perspective of a geophilophical plan, since this act, that is, "to create", is in itself a problem which is immanentely tied to every act of thinking. The act of creation, understood in its infinitive mode, is in open opposition to the stereotyped opinions which are typical of the so called common sense. The act of creation requires something which is quite different from the ready-made knowledge, from the ready-made thinking, in a way that it carries the thought to the indeterminated zones of a unimaginable chaos that only art is able to express. Since it is impossible to link it to ready-made images, the noology of creation can not be analyzed but in connection with the regularities and instabilities of Earth's flows.

Key-words: create, Deleuze, creation philosophy, immanence plan.

Ninguém duvida dos poderes da criação e dos valores da criatividade. Confundida com "imaginação", a "criatividade" é uma espécie de dogmatismo da educação, especialmente

\footnotetext{
${ }^{1}$ A pesquisa Paixões da Diferença: liberação de humores artísticos visa estabelecer relações entre artistas contemporâneos, intervenções, obras em rede, produções coletivas e projetos pedagógicos. O presente texto se configura como uma revisão de literatura quanto ao conceito de criação para melhor situar a perspectiva teórica junto a qual os trabalhos artísticos que consistem seu corpus serão posteriormente analisados.

2 Paola Zordan é doutora e mestre em Educação, bacharel em Desenho e Licenciada em Educação Artística pela Universidade Federal do Rio Grande do Sul. Professora da área de Didática das Artes do Departamento de Ensino e Currículo da Universidade Federal do Rio Grande do Sul. Na mesma instituição é professora do Programa de Pós Graduação em Educação e membro do grupo de pesquisa DIF: artistagens, fabulações e variações.
} 
no que tange ao ensino da arte. Há várias pesquisas sobre o assunto na aérea da administração e da publicidade, preocupadas com "geração de ideias" e "inovação de conceitos". A criatividade é, então, moeda no mercado de trabalho. Há também os trabalhos cognitivistas sobre criatividade: os que sustentam que criar é uma espécie de recurso para compensar falhas da inteligência, os que defendem a criatividade como "outro" tipo de inteligência, como faculdade necessária ao brain-storming ou como capacidade para solucionar problemas. A palavra "criatividade" carrega todas essas assertivas do "bom senso" empresarial e do senso comum do discurso educacional. Por isso, ao invés da "criatividade", uma educação para a Terra tem como potência o acontecimento criar.

Entretanto, o conceito de criação imanente ao pensamento geofilosófico de Deleuze difere das concepções humanistas e formalistas que marcaram o campo da arte. Criar não é uma qualidade essencial da humanidade e nem privilégio de uns poucos "inspirados". Também não é um "ato integrador de um processo existencial" (OSTROWER, 1978, p.56), algo que aprimore os indivíduos e se configure como "processo de crescimento contínuo no homem" (idem, p. 132). A criação não "provém de áreas ocultas do ser" (idem, p.55), tampouco transcende a experiência ou visa o alcance de uma compreensão. Criar não é formar, relacionar, configurar, estruturar, ordenar, significar e comunicar, como aponta Fayga Ostrower. É preciso sair das dimensões cognitivistas, ontológicas e fenomenológicas dos estudos sobre criação, para pensar o que é o criar enquanto acontecimento produtor de diferença.

Em seu trabalho sobre filosofia da criação, Marly Meira pensa uma pedagogia do acontecimento como prática estética (MEIRA, 2003). Tal pedagogia se abre às dimensões polifônicas da criatividade, que exigem uma "atenção difusa e espalhada", uma atividade avessa à lógica (MEIRA, 2003, p.47). Não há coesão de forças no criar, mas acasos e fragmentações. Ao considerar a natureza imprevisível do criar Virgínia Kastrup investiga a invenção ${ }^{3}$ como movimento de problematização das formas constituídas ou dos esquemas de recognição. Sua tese defende que esses coexistem com a potência inventiva e diferenciante (KASTRUP, 1997) que é a própria criação de problemas, tal como foi pensada por Bergson e Deleuze. Para ambas as autoras, as polifonias da criação e a problematização das formas de recognição divergem dos interesses da sociedade

\footnotetext{
3 "Buscando lançar luz sobre o que deve ser entendido por invenção, retomo a etimologia da palavra latina invenire, que significa encontrar relíquias ou restos arqueológicos (...). Tal etimologia indica o caminho a ser seguido: a invenção não opera sob o signo da iluminação súbita, da instantaneidade. Esta é somente sua fenomenologia, a forma como ela se dá à visibilidade. A invenção implica uma duração, um trabalho com restos, uma preparação que ocorre no avesso do plano das formas visíveis. Ela é uma prática de tateio, de experimentação, e é nessa experimentação que se dá o choque, mais ou menos inesperado, com a matéria." In: KASTRUP, 1997, p.6.
} 
capitalista dominante, que privilegia o dado, feito, o atual e não as indeterminações do criar ou do inventar.

"Pensar é criar, engendrar os próprios instrumentos de solução para os problemas" (GIROTTO, 1998, p.165), escreve Nara Lúcia Girotto em sua pesquisa genealógicacartográfica sobre a criação. Não restrito ao campo da arte, criar é um acontecimento que tange toda prática docente: "o espaço escolar comporta um tempo de criação/invenção na prática pedagógica" (idem, p,164). Girotto procura mostrar como o cotidiano de sala de aula requer posturas inventivas e como os movimentos do pensamento fazem rizomas, conceito que na cartografia esquizoanalítica exprime a proliferação de conexões e disjunções num território atravessado por vários devires. Todavia, "a criação não pode ser ensinada": requer a experiência, essa dimensão intransitiva, intransmissível (idem, p.13). Sem experimentação, criar é impossível, de modo que criar implica entrar nas zonas instáveis das experiências. Sobre o terreno movediço da criação os problemas se constituem. Tanto Girotto como Kastrup, abordam a intempestividade da criação ou da invenção ${ }^{4}$.

Acontecimento intemporal, a data de uma criação pode dizer de um material, de um corpo artista, de uma paisagem existencial, mas nada sobre as forças envolvidas no criar. O disseminado dito "nada se cria, tudo se transforma"5, ensina que nada é excepcionalmente novo, original, e sim modificação e alteração de estados preexistentes, já dados. Seguindo a lógica daquilo que já existe, já é dado, atual, real, palpável, podese dizer que tudo o que se conhece é criação. Daí, apesar do inevitável embate com a mutabilidade das coisas, é muito fácil confundir o que se conhece e já foi criado com o que se toma por "verdade". Como expressão do conhecimento e da verdade, a criação se torna uma instância transcendente, de modo que tudo o que resta ao homem é "criatividade" para transformar o que já foi feito. Deus expressa a idéia tradicional de criação, a passagem da não existência para a existência, o fiat lux, o ponto original, absoluto, Uno e Múltiplo do qual tudo emana, do qual todo o universo não é mais do que mera expansão, variação e modificação. Se tudo o que existe, foi criado, é "verdadeiro", toda verdade envolve uma criação. A verdade vem de certas condições de criação na medida em que "é somente o que o pensamento cria" (DELEUZE; GUATTARI, 1992,

\footnotetext{
${ }^{4}$ Para Fayga Ostrower, a criação é o processo atemporal da arte, enquanto que a invenção, preocupada em fazer algo "novo", inédito e insólito só inventa bobagens, besteiras (os termos que Fayga usa não são exatamente esses, mas vacuidade, vazio, etc). Para ela, "mais do que inventar, mais do que produzir algum fenômeno novo, criar significa dar forma a um conhecimento novo que é ao mesmo tempo reintegrado em um contexto global". Apesar de ser adepta do abstracionismo, sua crítica à pop-art, arte conceitual e outros movimentos da arte contemporânea, é bastante contundente e acompanha um certo lamento pela crise de criatividade dos "tempos atuais" (no caso, os anos setenta do século XX). Cf. OSTROWER, Fayga. Criatividade e processos de criação, p. 134-135.

${ }^{5}$ Conhecido como Lei de Lavoisier, esse dito sintetiza a explicação química das contínuas transformações da matéria. Antes da comprovação científica, o conceito de universo como matéria em contínua transformação aparece com Giordano Bruno, no século XVI.
} 
p.73), jamais uma verdade pronta, recebida de uma suposta instância transcendente. Os problemas são as condições para a criação. Criar é uma maneira de se orientar sobre um campo problemático, o plano de imanência pré-filosófico. A criação é um lance de dados, um jogo imprevisível do acaso, ou seja, não tem nada a ver com idéias transcendentes, eleições do que seja verdade, sendo que uma criação não responde a julgamentos, juízos de valor, tampouco serve para mostrar certezas ou enganos. Criar, em si, é um problema. Conceito implicado com a vida, a criação suscita questões sobre o ser, a existência e sobre todo o mundo fenomenológico. Se criar, como rezam as concepções tradicionais, fosse fazer existir, se suporia que o ainda não criado simplesmente não existisse. Todavia, o in-criado pode vir a ser criado e, mesmo não sendo real, é possível, portanto, que não deixe de existir. Criar não se relaciona com ser, mas com devir, não é um problema ontológico e nem fenomenológico, é um problema noológico, diz respeito às imagens de pensamento.

A noologia envolta na criação leva grande parte dos autores que tratam do assunto a abordarem o problema dos clichês. Os clichês são imagens prontas, dadas de antemão, lugares-comuns do pensamento. Criar é desmanchar os clichês, romper com as opiniões e pré-concepções, deslocar campos de referências, quebrar as convenções, perverter os modelos, sair do império das representações, das imagens dogmáticas de pensamento. Isso supõe que as criações sejam originais, singulares, heterogêneas, independentes de serem, ou não, obras de $a r e^{6}$. A singularidade e os processos de singularização são tomados como qualidades intrínsecas da criação, de modo que o acontecimento criar acaba uma sinonímia para o singular, na qual as singularidades são compreendidas como as próprias criações, sendo estas potencializadoras de vida (FONTEBASSO, 2002).

Há uma concordância geral no que tange ao vitalismo da criação e a sua importância para a saúde mental. A impossibilidade de criar é uma espécie de morte e a doença é abordada como a falta de criação (POZATTI, 2003). O clichê, a padronização, os lugarescomuns aparecem como sintomas contemporâneos da estratificação do desejo. A estratégia passa a ser desestabilizar o já conhecido, o dado, as imagens acomodadas, inventando o que Deleuze e Guattari chamam máquinas de guerra, dispositivos capazes de produzir fissuras nos segmentos mais duros, essas mesmas passagens de sempre, os caminhos já percorridos que conduzem às soluções prontas. A função dessas máquinas é fazer linhas de ruptura que cortam e bifurcam os segmentos estratificados dos clichês. A motivação desse funcionamento é criar novos modos de existência, abertos a plenitude da vida.

\footnotetext{
6 "Singularizar por meio da arte é criar. Criar implica em traçar linhas de fuga da subjetividade, sair do clichê". Cf. FILHO, 1993. p.93.
} 
Vilão a ser aniquilado, o conceito de clichê acaba virando o próprio clichê dos afectos ruins e da pobreza da criação: ilusão barata, vendida a cada esquina, impedindo a manifestação das singularidades. Despoluir o olhar dos clichês, como Deleuze tantas vezes propõe, não é afirmar uma espécie de salvacionismo por meio da criação. Primeiro porque existe uma imensa dificuldade em saber quando uma imagem é um clichê. O que é clichê em algumas circunstâncias pode não ser em outra. Um clichê é sempre uma recognição, um hábito, uma representação instituída, independente da sua incidência e de seu número de reproduções. Pois, um objeto de reconhecimento, um hábito criado e mesmo a mais universal das representações, apresentam margens indeterminadas que podem colocar em fuga os estereótipos que os circundam. Há devires até mesmo no que se estabelece como clichê. O problema não são as referências, a "cara" do clichê, muito menos o lugar-comum. O problema é o que se faz com todas essas coisas que povoam a paisagem, enchendo os olhos e todos os sentidos do corpo. Antes de limpar a paisagem é preciso olhar o clichê sem preconceitos, não como "empobrecimento" da criação, mas como mais uma de suas matérias, como estranha riqueza do submundo. Em segundo lugar, o salvacionismo não se sustenta porque a criação aniquila e dilacera com seus movimentos, portanto, mais mata do que salva.

Os perigos envoltos na criação e a implicação desta com o caos não deixam de ser um dos lugares-comuns presente nas teorizações sobre esse assunto. A criação é concebida como o que se extrai do caos, o que resulta dos mergulhos no caos, o que se determina e se recorta da profusão caótica. A tendência das mais variadas correntes teóricas é opor o caos e a criação. Criar é algo que conecta, liga algo a algo, descrevendo um movimento que saí do invisível, do indizível e vai traçando diagramas, visibilidades e enunciados. A criação pressupõe uma confusão originária, algo como um plasma caótico do qual é necessário emergir. "Todos os processos de criação começam nesse estado de profunda inquietação e tensão" observa Fayga Ostrower (1990, p.257). Embora muito se fale e escreva sobre as intensidades da criação, essa é quase sempre descrita como um processo de atualização, implicado em desdobramentos, reestruturações e delimitações. Quando Ostrower mostra que a criação incorpora um processo dialético, pois ao mesmo tempo constrói e destrói, trata a criação como o trabalho atual do corpo em movimento. Para autora, o criar não pode ser desvinculado das possibilidades e dos limites da matéria. A criação está sempre jogando com os limites, os quais funcionam como "áreas indicativas" (1978, p.160) no criar. O limite é uma espécie de garantia para não se cair no abismo que está tão perto e evitar ser engolido pelo turbilhão ativado quando se cria. O aspecto transformador da criação (transformação que é outra das unanimidades teóricas sobre o conceito) também tende ao atual, na medida em que a criação é 
concebida como atividade de definir algo desconhecido, situado nas fronteiras entre o caos e o cosmos abarcado pelo conhecimento.

Sabe-se que criar é fazer crescer. Criar filhos, orquídeas, gado. A noção geral é de que a criação pressupõe um criador, visto que a própria realidade só existe porque deve ter sido criada. Não há cultura que não tenha sua cosmogonia, seu mito sobre a criação. Há sempre uma causa para a existência do mundo: calor, amor, energia, desejo, luz, som e até os números, de acordo com as explicações da cabala, sistema judaico de compreensão da ordem cósmica. A tendência geral de todos os mitos é contar a criação como "descida" da luz para matéria. Não que o mundo seja sempre o resultado de uma queda, mas de uma evidente diferenciação. Junto aos movimentos descendentes, é comum a criação acompanhar imolação, desmembramento e sacrifício. O Criador é aquele que ao cantar, moldar, talhar, cortar, cria a terra e os homens. Para os dogons ${ }^{7}$, tecer, plantar, dançar e copular são expressos numa mesma palavra, a qual também significa criação (MACLAGAN, 1997,p. 31). Um criador, antes de ser um demiurgo, é apenas corpo que faz o acontecimento do mundo. "Não há Criador, senão uma infinidade de poderes criadores, que coletivamente formam a eterna substância", afirma a inventora da Teosofia. Essa substância é chamada de Akasha, termo provavelmente copilado por Blavatsky em suas andanças pela Ásia. Essa essência da vida, substância da criação, "é inescrutável, e daí que não seja objeto de especulação para nenhum filósofo verdadeiro" (BLAVATSKI, 2002, p. 25).

A criação tem os mesmos mistérios que a vida. Os movimentos criadores, a imprevisibilidade de seu devir, são insondáveis. Antes de bandeira de resistência ao império dos clichês, criar é micro-revolução. Quando escrevem que "criar é resistir", Deleuze e Guattari (1992, p. 143) pensam em devires e acontecimentos, potências virtuais não necessariamente atualizadas ou em processos de atualização. A estratégia é resistir ao atual, seguir sensações e devires, experimentar os territórios virtuais do plano de imanência. Não se trata de transformar o estado atual num outro atual; criar é um processo de virtualização no virtual. A criação é uma composição atual, mas criar é um acontecimento virtual. Criar é compor o caos virtual com matérias da virtualidade, imagens de pensamento. Conceber a criação como virtual é pensá-la no plano de composição da arte. Criar é um processo intuitivo próprio do pensamento, a invenção da vida que o habita, seus bandos, seus povos, totens e deuses. Criar é receber afectos e dar cores para a paisagem e para as figuras, compondo matérias de expressão. 0

\footnotetext{
${ }^{7}$ O povo dogon, que vive nas encostas leste do Rio Niger, Africa oriental central, os quais foram estudados por antropólogos o século XX, especialmente Dieterlen e Griaude, cujas publicações constituem mote para reflexões etnográficas e cosmogônicas. O mito do ovo dogon serve, inclusive, de inspiração para que Deleuze e Guattari desenvolvam, em O Anti-èdipo e Mil Platôs: capitalismo e esquizofrenia, o conceito de corpo sem órgãos.
} 
conhecimento, as imagens formadas de um pensamento disciplinado, é o que dele fazem as criações, com suas figuras e paisagens infinitas. A criação, filha do criar, "toma o lugar do próprio conhecimento" (DELEUZE, 1976, p. 145). Criar é a ação do pensamento, aquilo que o movimenta, revoluciona, faz com que ele aconteça.

Em O que é filosofia? Deleuze e Guattari definem a filosofia como criação de conceitos cujos devires traçam um plano de pensamento. Esse plano não é oposto ao caos, mas a ele se diferencia. Os elementos do plano são caóticos e definem campos caósmicos, num cosmos indiscernível do caos, que traçam uma superfície de sentido, um plano de imanência povoado de criações. Cada tipo de plano tem seu tipo de criações, suas variações de velocidade, seus estilos e agenciamentos. O plano de imanência científico cria functivos e o plano da arte, perceptos. Não há uma fronteira entre pensar e criar, apenas variações: o pensamento traça o plano e a criação o povoa de conceitos. Os devires se criam nos conceitos, nos perceptos, nos functivos. Criações que, imbricadas constantemente, desterritorializam a matéria que sobrevoam. Os planos virtuais da arte, da filosofia e da ciência criam máquinas, veículos, alegorias e artifícios para suportar os corpos na andança errante dos fluxos, na passagem louca de devires. Criar é, mais do que tudo, fabricar um corpo sem órgãos. Corpo desmembrado de Dioniso ${ }^{8}$, corpo renascido do eterno retorno que expressa a passagem das afecções. Criar dilacera porque é uma violência ao pensamento, não uma acomodação. Criar é fazer a diferença, não a diferença que faz algo "original", pois as criações não são origens, somente nascimentos, embora também sejam mortes. Jamais possuem verdades essenciais. Não são oposições ao atual e ao que foi criado e também não são alteridades, modificações ocasionais das séries de sentido. A criação é a diferença em si mesma, diferença extemporânea, o que os gregos chamavam Aion, o tempo do acontecimento.

Criar é movimento involuntário do acaso sobre os acontecimentos singulares que individuam o pensamento. Criar não tem a ver com a imagem dogmática de um Criador, não é o ato de um demiurgo, arquiteto, artista ou forjador. A expressão criadora, criação que se atualiza, maquina a arquitetura inacabada do mundo, ao mesmo tempo em que padece das forças incorporais que agem por todas as criações. Criar é uma experiência feiticeira, um vôo de vassoura, uma prosa com almas de outro mundo. Ninguém cria sem sair do corpo, mesmo que dance. Dançar é sair do corpo criando movimentos. Só se cria com o corpo, mas fazendo dele um corpo diferente, estranho, matéria para um devir que não pertence ao nome e a pessoa que o configuram. Uma esquizoanálise da criação

\footnotetext{
${ }^{8}$ Deus grego de provável origem cretense, Dioniso, o deus do vinho, Baco para os romanos, era uma divindade de duplo nascimento. Herdeiro de Zeus, Júpiter ou o pai celestial dos romanos, diz o mito que era um menino a brincar quando foi despedaçado e devorado vivo pelos Titãs, sendo salvo porque a deusa Palas-Athena/Minerva segurou seu coração antes que o comessem.
} 
pergunta: em que tipo de acontecimentos se cria? Em que lugares? Em que momentos? De que maneiras?

Não existe um método para se criar. A criação acontece junto a interceptores, a corpos e matérias que fazem escoar imagens de pensamento. Os interceptores funcionam como válvulas, vetores que desembocam em superfícies onde são dispostas forças problemáticas. Um interceptor guia e limita os movimentos do pensamento na matéria caótica da Terra. Os interceptores costumam muito bem se confundirem com a sua matéria, mesmo quando se apresentam na discernível figura do Professor. A única maneira de aprender é criar virtualidades sobre as matérias que se experimenta. Criar é pensar um modo de fazer junto, não igual, mas junto à mesma matéria, perante as mesmas intercepções. Ação micropolítica, criar é se arriscar no erro, na besteira, na completa ignorância da criação. Toda a criação comporta demônios e perigos que correm o risco de padecerem de juízos negativos, pois, enquanto houver razão, nunca estará livre das críticas, das indiferenças, das rejeições e das condenações. A razão é a faculdade do pensamento estabelecer relações, identificar dados, elaborar normas e definir verdades. Embora a criação não se oponha à razão, difere dela por natureza. A razão defende valores e propriedades, enquanto a criação questiona, problematiza e desterritorializa.

A verdade não é o que julga a razão, mas o processo de criação que a produz. A destruição ativa, intrínseca ao caos junto ao qual acontece esse processo, cria novos valores. Ao romper com os valores imutáveis, que se dizem eternos, que se dizem a Verdade, a transformação dos valores cria o super-homem, aquele que supera a si mesmo por meio da criação. Não o homem subjugado em nome de uma verdade, mas força inumana que cria sua própria verdade e se torna "a medida e o valor de todas as coisas", aquilo "que cria sentido para a terra" (MACHADO, 1997, p. 69). A criação é vontade de potência, anseio de vida. A doutrina do eterno retorno equaciona o querer com o criar, pois, a vontade de potência é, por natureza, criadora. Entretanto sempre implica a passagem pelo niilismo reativo, rugido ferino que nega a verdade para poder criar. Por isso, o Zaratustra ${ }^{9}$ de Nietzsche ensina a coragem para se deixar ir de encontro com o nada, sem o qual não se consegue a alegria de criar. Criar é a transvaloração, a afirmação dionisíaca da criança que brinca sob as presas afiadas do leão.

"Quanto maior e mais absoluto é esse nada, mais poderoso e radical se torna esse ato criador" (MACLAGAN, 1997, p.13). O nada não é o que era antes do mundo começar, um

\footnotetext{
${ }^{9}$ Nietzsche cria um personagem, homônimo do profeta persa, que encarna as voltas ativas e reativas, estas últimas a serem sempre superadas, que erguem o conceito de eterno retorno, vital para a perspectiva deleuziana do que vem a ser a criação.
} 
diabo mais velho que 0 mundo, o Pai das Trevas $^{10}$ não é um caos de escuridão indiferenciada, mas a possessão demoníaca de todos os devires numa velocidade louca e infinita de $n$ fragmentos e partículas. O caos "é um fundo infinitamente agitado e formigante de determinações flutuantes e não ligadas" (TERRÉ, 1994, p.44). A experiência niilista é um modo de se possuir do caosmos para dele se diferenciar. "Toda a criação supõe a anulação desta fusão caótica" (MACLAGAN, 1997, p.14), uma disjunção que parte seus fluxos, não para seccioná-los ou esquadrinhá-los em imagens, mas como diferencial que faz espalhar as linhas de devires sobre a pele da Terra.

A criação sempre produz, mesmo que, sob um molde geral, esteja reproduzindo. Há um potente devir esquizofrênico no criar, experiência incorporal que não acontece fora do corpo e jamais se deixa aprisionar pela matéria que o exprime. Na matéria se dão os confrontos entre corpos diferentes, onde as peles se misturam produzindo os afectos necessários para que aconteça a criação. Sem afecções corpo-a-corpo, sem toque, não se cria. Sem experimentar um corpo, ainda que seja para transfigurá-lo, sacrificá-lo, diluí-lo, abandoná-lo, não há criação. A criação é psicótica, irrompe em surtos de amor e morte, sangue e esperma, decomposições. Atualiza o virtual na matéria, dando expressão para as virtualidades do criar. Terra que não é máquina, nem imenso organismo, mas caráter nunca atualizado do mundo, "caos por toda a eternidade, não no sentido de ausência de necessidade, mas de ausência de ordem, divisão, forma, beleza, sabedoria e como quer que se chamem nossos antropomorfismos estéticos"(NIETZSCHE, 2001$, p.136) $)^{11}$.

Criar na matéria é sempre um trabalho, exercício de uma vontade obstinada sobre a força do material. Trata-se de um trabalho que "não é somente expressar-se, é possibilitar que esse material também se expresse" (MEIRA, 2003, p.22). A matéria fala, ensina, intercepta. O material pelo qual a matéria se expressa é sempre extraído da terra. Superfície de criações e devorações, o solo variado da Terra é a grande escola. Terra, a primeira das mestras, a desterritorializada, malhada, imantada de rizomas, de vias diversas que se cruzam, se bifurcam, se encontram e seguem em linha de fuga. Ao "tomar o caminho de uma linha de fuga que é sempre o estopim da criação" (TADEU, 2002, p.52), as desterritorializações arrastam o corpo para o fora, o faz sair de si mesmo e irromper numa outra coisa. Há tantos modos de criar quantas forem as possibilidades de linhas de fuga. Tratamento detectável em dados territórios, o estilo de uma linha se explica na maneira da criação. A infinidade de maneiras possíveis lança o pensamento ao

\footnotetext{
10 "Primeiro nasceu o Caos. (...) De Caos nasceram Érebo, a treva debaixo da Terra, e a Noite". PINSET. Mitos e Lendas da Grécia Antiga. São Paulo: Melhoramentos/USP, 1978, p.12.

${ }^{11}$ Cf. Aforismo 109 de A gaia ciência.
} 
incontável das possibilidades do caos, abrindo-o ao espaço liso, nômade, propício à invenção de modos de vida e a transvaloração.

Constante desterritorialização, criar transforma a paisagem, potencializa a vida e a novidade de cada instante. Por outro lado, produz imagens de pensamento para reterritorializar a vida num traçado de plano, um projeto de vida, uma obra de arte. A arte reterritorializa o caos sem congelar suas multiplicidades em imagem, criando perceptos. Os perceptos, assim como os conceitos, têm inúmeros devires e se abrem a infinitas possibilidades de criação. Os devires são afectos, forças que atravessam blocos de sensação criando a obra de arte. Obra que é dispositivo estético para provocações e dispersões da opinião estandardizada. Criação de perceptos, a arte é uma máquina que transforma afecções e percepções em devires incorporais, corpos sem ossos que se sustentam sozinhos. Criar é dispor potências; a criação é a potência em ato.

E o que move a criação, senão o desejo? Desejo que está sempre a seguir um fluxo, uma linha de vida que se confunde com a morte e com a vida incorporal. Não há vida sem a intensidade dissonante provocada pelo caos. Plano de velocidade infinita, variação contínua, multiplicidade, movimentos de expansão e contração, dissipações, diacronias, é superfície de Géia ${ }^{12}$, a desestabilizadora da ordem e dos poderes estabelecidos. Força divina sem máscara e sem rosto, casca do ovo, a matéria é imprevisível, caósmica, esquizo: nem bem onda e nem bem partícula, mas puro movimento e oscilação. Tal qual a vida, o caos não pode ser representado. O caos não está fora do plano, mas é marcado por um fora selvagem, impensado, que o diferencia. Feiticeira, "a linha do Fora é uma linha mortal" (TERRE, 1994, p.46).

Conceber a criação junto à filosofia de Deleuze é envolvê-la com o não pensado, o fora. Pensar a criação é seguir os movimentos de atualização do virtual e os turbilhões virtuais que o pensamento descola da experiência atual. Carregada de virtualidades, a criação comporta o que não está dado, o que não foi feito, o que não se sabe, o que não dá para imaginar de antemão, o que é impossível de se prever. A singularidade de toda a criação mostra cem mil pontos de vista, mil modos de se acercar daquilo que desconhecemos. Desmedido, inesgotável, o fora é aquele pensamento que ainda não tem imagem, que é apenas intensidade, pulsar vivo e irreversível do devir. O lado de fora carrega a estranheza do impensado, do que emite partículas de caos. São partículas selvagens que nos obrigam a criar novos modos de se habitar o plano, de produzir interioridades, dobras para abrigar o ser daquilo que Artaud chamou uma "outra ordem do mundo", da

\footnotetext{
${ }^{12}$ Géia ou Gaia é como os gregos chamavam a Terra, sendo essa uma deusa primordial apartada do Céu. Para Deleuze e Guattari, esse imenso corpo onde nossa vida se desenrola é uma molécula gigante, não organizada, mas viva.
} 
qual nada sabemos, mas cujo "número e ordem de suposições possíveis é precisamente infinito" (1986, p. 154). O problema da criação é o impossível devir em que se embrenha. A criação é caótica, trabalha com o caos material, com o fora do pensamento, como um incriado do qual ela nunca se separa. A intensidade do fora perverte os compossíveis, exprimindo novos agenciamentos para as matérias. Paradoxalmente, um esquisito sentido de ordem faz com que as criações procurem virtuoses, submissão de uma técnica a um gosto apaixonado que transforma o gesto em arte. Trata-se de manejar a Natureza, tornar a Terra melhor, mais habitável, um lugar para se viver. Mas este paraíso de criações feitas para se poder habitar o caos escapa da ideia de perfeição. A criação é a linha errante do pensamento, a cada instante recebendo novos signos que forçam o pensamento a se modificar e a criar novos conceitos.

\section{Referências}

ARTAUD. Escritos de Antonin Artaud. Porto Alegre: LP\&M, 1986.

BLAVATSKY, Helena. Síntese da doutrina secreta. São Paulo: Pensamento, 2002.

DELEUZE. Nietzsche e a filosofia. Rio de Janeiro: Editora Rio, 1976.

DELEUZE \& GUATTARI. O que é a filosofia? Rio de Janeiro: Ed.34, 1992.

KASTRUP, Virginia. A invenção de si e do mundo- uma introdução do tempo e do coletivo no estudo da cognição. PUC-SP. Tese de doutorado. São Paulo: Programa de Pós-graduação em Psicologia Clínica, 1997.

FILHO, Fernando Silva Teixeira. Subjetividade estética: o gesto da sensação. São Paulo: PUC/SP. Dissertação de Mestrado. Programa de Pós-graduação em Psicologia Clínica, 1993.

FONTEBASSO. A aprendizagem na educação de jovens e adultos: "tempo fora dos eixos". Porto Alegre: FACED/UFRGS. 242f. Tese (Doutorado em Educação). Programa de Pós-graduação em Educação da Universidade Federal do Rio Grande do Sul, 2002.

GIROTTO, Nara Lúcia. Crônicas de uma prática (re) inventada: a discussão da criação/invenção imanente à prática docente. Porto Alegre: UFRGS/FACED. 181f. Dissertação (Mestrado em Educação) - Programa de Pós-graduação em Educação da Universidade Federal do Rio Grande do Sul, 1998.

MACHADO, R. Zaratustra, tragédia nietzschiana. Rio de Janeiro: Jorge Zahar, 1997.

MACLAGAN, David. Mitos da criação. Trad. Francisco Perales. Madrid/Rio de Janeiro/ Lisboa: Ed. Del Prado, 1997.

MEIRA, Marly. Filosofia da criação: reflexões sobre o sentido do sensível. Porto Alegre: Mediação, 2003.

NIETZSCHE, Friedrich. Gaia Ciência. $f$ 109. São Paulo: Companhia das Letras, 2001. 1998.

Assim falou Zaratrusta. Trad. Mário Silva. Rio de Janeiro: Civilização Brasileira, 
OSTROWER, Fayga. Criatividade e processos de criação. Petrópolis: Vozes, 1978.

PINSET. Mitos e Lendas da Grécia Antiga. São Paulo: Melhoramentos/USP, 1978.

POZATTI, Mauro. Em busca da inteireza do ser: formulações imagéticas para uma abordagem transdisciplinar e holística em saúde e educação. Porto Alegre: FACED/UFRGS. 138f. Tese (Doutorado em Educação). Programa de Pós-graduação em Educação da Universidade Federal do Rio Grande do Sul, 2003.

TADEU, Tomaz. A arte do encontro e da Composição: Spinoza+ Currículo+ Deleuze. _In: Educação \& Realidade: Dossiê Gilles Deleuze. UFRGS/FACED. Porto Alegre, $\mathrm{n}^{\circ} .27$, vol.2, jul/dez, 2002.

TERRÉ. Ojos Rojos: tientos sobre algunas fórmulas deleuzianas. In:Archipiélago... Madrid, №.17, p.42-51, jun. 1994, p.44. 